\title{
RUPTURAS E CONTINUIDADES DAS POLÍTICAS PÚBLICAS PARA A EDUCAÇÃO PROFISSIONAL NO BRASIL ENTRE 2003 E 2015
}

\author{
RUPTURES AND CONTINUITIES OF PUBLIC POLICIES FOR VOCATIONAL \\ EDUCATION AND TRAINING IN BRAZIL BETWEEN 2003 AND 2015
}

D. MADURO SILVA ${ }^{1, *}$

1 Universidade Federal de Minas Gerais, Pró-Reitoria de Extensão, Brasil

\section{ARTICLE INFO}

Article history:

Received 2018-07-05

Accepted 2018-10-15

Available online 2018-10-31
Palavras-chave: Educação profissional. Ensino médio técnico. Políticas Públicas.

Keywords: Vocational education and training; Technical high school; Public policy

*Autor correspondente:

E-mail: denisebianca@ufmg.br

RESUMO. No Brasil entre 2003 e 2015 tem-se um contexto de aposta, pelo governo federal, na educação profissional como motor do desenvolvimento social e econômico. Este trabalho visa apresentar e discutir as principais iniciativas em políticas públicas para a educação profissional no referido período, com especial atenção para o nível médio técnico. Em base à revisão documental e bibliográfica, são analisadas as lutas ideológicas e políticas na formulação e implementação das iniciativas educacionais, explicitando-se a ação dos grupos de poder na disputa pela direção do Estado. Conclui-se ressaltando as rupturas e continuidades históricas encontradas no tratamento dado à educação profissional de ensino médio técnico no período em análise. O novo modelo de educação profissional implantado no governo federal após as eleições de 2003, pauta-se na verticalidade da oferta de educação profissional e tecnológica, na articulação com o ensino regular, no aumento da escolaridade do trabalhador, na interação com o mundo do trabalho, e no apoio à escola pública. No entanto, esses ideais destacados dos discursos oficiais do governo, encontram embates ideológicos, políticos e estruturais para sua implementação, que condicionam os resultados alcançados. Desta forma, as políticas públicas do governo federal para a educação profissional analisadas para o período refletem e atualizam as disputas por poder presentes historicamente nas sociedades capitalistas e no Estado brasileiro. 
ABSTRACT. In Brazil between 2003 and 2015 there is a context of commitment by the federal government in vocational education and training as the engine of social and economic development. This paper aims to present and discuss the main initiatives in public policies for vocational education and training in the mentioned period, with special attention to the technical high school level. Based on the documentary and bibliographical review, the ideological and political struggles in the formulation and implementation of the educational initiatives are analyzed, exploring the action of the power groups in the dispute for the direction of the State. It concludes by highlighting the ruptures and historical continuities found in the treatment given to technical high school level. The new model of professional education implemented by the federal government after the 2003 elections is based on the verticality of the offer of vocational education and training, on articulation with regular education, on the increase of workers' schooling, on interaction with the world of work, and in supporting the public school. However, these ideals that stand out from official government discourses find ideological, political and structural obstacles to its implementation, which impacts the results achieved. In this way, the public policies of the federal government for vocational education and training education analyzed for the period reflect and update the power disputes historically present in capitalist societies and in the Brazilian state.

\section{Introdução}

Conforme Castioni (2012, p. 48), nos períodos recentes de neoliberalismo e processos de globalização, a sociedade irá se assentar sobre os ganhos absurdos dos circuitos financeiros internacionais: "[...] em 1980, no Brasil, os salários representavam metade do Produto Interno Bruto (PIB) e hoje não passam de 1/3". Este quadro, para o autor, teve sinais de redução apenas nos últimos anos em que se pôde observar a reintrodução na agenda governamental do enfoque de articulação federativa e da política de desenvolvimento regional: reestruturaram-se fundos constitucionais e começou-se a pensar projetos de cunho mais horizontal envolvendo diversos ministérios. Conforme Dore e Lüscher (2008), credita-se à gestão do presidente Lula o pagamento da dívida com o Fundo Monetário Internacional - FMI - que liberta o país do estrangulamento e aporta um considerável investimento em políticas de redução das desigualdades sociais como o Bolsa Família e o Fome Zero. Segundo Amorim (2013) o gasto público brasileiro com educação como percentual do PIB saiu de 3,5\% em 2000 para 5,5\% em 2008.

Entre 2002 e 2014, o mercado de trabalho brasileiro teve um desempenho positivo, em um cenário de inclusão produtiva. O desemprego diminuiu de 12,9\% em 2002 para 4,9\% em 2014, entre 2002 e 2014, a renda decorrente do trabalho cresceu em média 2,5\% ao ano em termos reais, o emprego formal cresceu expressivamente, ultrapassando emprego informal a partir de 2007, e "a maioria do aumento da inserção no mercado de trabalho formal entre os mais pobres se concentrou em um grupo específico de trabalhadores: jovens que concluíram o Ensino Médio" (SILVA; ALMEIDA; STROKOVA, 2015, p. 01). Nesse cenário, a educação profissional, vista como motor do desenvolvimento econômico, no 
governo de Luiz Inácio Lula da Silva (2003-2010) e no governo de Dilma Vana Rousseff (2011-2016 1 ), recebeu massivos investimentos. O presente trabalho apresenta, em base à revisão documental e bibliográfica, as políticas públicas do governo federal dirigidas à educação profissional, em especial ao ensino médio técnico entre os anos de 2003 e 2015. Ao final analisa-se, sob a ótica da luta pela hegemonia no Estado (GRAMSCI, 2004), como as iniciativas encontradas nesse contexto representam mudanças e continuidades no tratamento dado à educação profissional, em especial ao ensino médio técnico, no país.

\section{Desenvolvimento}

\section{Características do ensino médio técnico}

No Brasil, a educação profissional de nível médio é ofertada pelas redes federal, estadual, municipal e privada (responsáveis respectivamente por aproximadamente 19\%, $30 \%, 2 \%, 49 \%$ das matrículas do ensino médio técnico em $2015^{2}$ ), sendo que, apesar da descentralização levada a cabo nos anos 1980 e 1990, em todas essas esferas existem aportes de recursos da União.

Segundo Souza (2004), o desenho institucional condiciona o incentivo ou o constrangimento à descentralização (recompensas e sanções). Nessa linha de análise, nos anos 1990, o Fundo de Manutenção e Desenvolvimento do Ensino Fundamental - FUNDEF, Lei n. 9424/96 (BRASIL, 1996) é um exemplo, para a autora: lançado em 1996 e em vigor a partir de 1998 garantiu a distribuição dos recursos condicionado à matricula, ou seja, o recurso acompanha o aluno. Souza (2004) destaca as regras do FUNDEF, de caráter redistributivo por teto mínimo a ser dispendido com cada aluno, e quando os recursos vinculados às esferas municipais e estaduais não atingem esse mínimo, o governo federal suplementa a diferença. O Fundo de Manutenção e Desenvolvimento da Educação Básica FUNDEB (BRASIL, 2007a) amplia o campo de atuação do fundo e atribui cotas estaduais e municipais distribuídas por número de aluno matriculado na rede pública, por tanto, continua a função redistributiva de recursos (ARAÚJO; 2015). Para Augusto Silva (2013, p. 64-65) o FUNDEF deu estabilidade à escola pública brasileira, devido à regularização de salários de professores, melhorias nos equipamentos e prédios e a elevação da quantidade e qualidade na merenda escolar. Ainda conforme o autor, no FUNDEB a maior parte (cerca de $60 \%$ do total) passou a ser consumido pelo pagamento a gestores, professores e funcionários;

\footnotetext{
${ }^{1}$ O segundo governo Dilma foi interrompido no primeiro semestre de 2016 por meio de um impeachment, o qual muitos intelectuais caracterizaram como um golpe de Estado. Ver posicionamento da Latin American Studies Association - LASA em, https://www.brasil247.com/pt/247/mundo/249088/Intelectuais-confirmam-Dilma-foi-v\%C3\%ADtima-de-golpe.htm. Acesso: 25/12/2017.

${ }^{2}$ Com base no número de Matrículas na Educação Profissional -Ensino Regular, sem contabilizar a Educação de Jovens e Adultos -EJA- e Normal/Magistério, por Etapa de Ensino (ensino médio) e Dependência Administrativa - 2015.
} 
outros $27 \%$ devem ser destinados à manutenção e ao funcionamento das instituições de ensino; $6,6 \%$ para reformas e construções de novas escolas; $6 \%$ para os chamados encargos sociais (previdenciários e trabalhistas) e $0,4 \%$ no setor de pesquisa e desenvolvimento.

\section{Gráfico 1 - Matrícula Regular no Ensino Médio Técnico por Dependência Administrativa no Brasil em 2015}

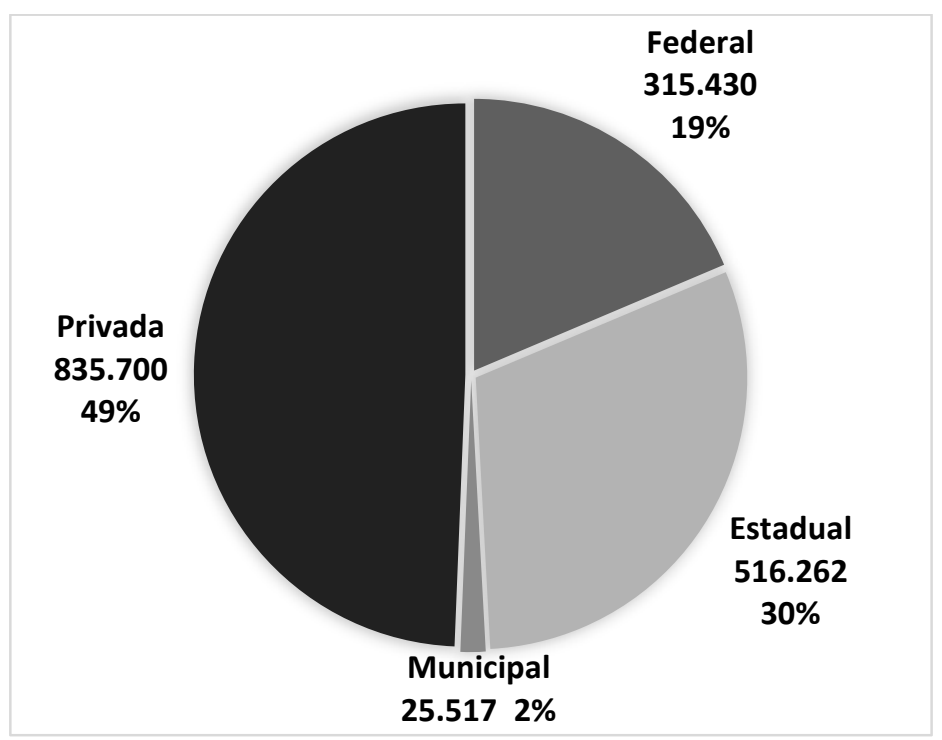

Fonte: Sinopse Estatísticas da Educação Básica (INEP, 2016).

Apesar dos novos membros do Ministério da Educação a partir de 2003, incluindo acadêmicos, criticarem os formatos dos cursos concomitante e pós-médio, por terem como referencial o desenvolvimento de competências e serem assim considerados submissos aos interesses do mercado (RAMOS, 2002), os mesmos formatos se mantiveram na nova normativa, o Decreto n. 5.154/2004 (BRASIL, 2004), que revoga o Decreto n. 2.208/97 (BRASIL, 1997). Porém o novo decreto também retoma a educação profissional técnica de nível médio integrada, de modo a conduzir o estudante à habilitação profissional ao mesmo tempo em que conclui a última etapa da educação básica.

A volta dos cursos de formação profissional de nível médio integrada ao técnico foi duramente criticada por intelectuais como Castro (2008), políticos e gestores estaduais de educação, passando por diversos embates ideológicos e administrativos para sua implementação no território nacional apesar do respaldo legal fornecido pelo governo federal a partir de 2004 e de suas políticas de fomento, por exemplo por meio do Brasil 
Profissionalizado e da política de expansão da Rede Federal de Educação Profissional, Científica e Tecnológica - RFEPT, discutidos mais à frente.

Nos últimos anos, o MEC voltou a integrar os cursos acadêmicos aos profissionais. As razões parecem ser de duas naturezas. Uma delas é puramente ideológica. A secretaria do MEC incumbida de cuidar do ensino técnico passou a ser dominada por um grupo que, há muitos anos, defende as idéias criadas por Gramsci e englobadas sob o termo 'politecnia'. Seus defensores pregam uma escola técnica única e integrada, ensinando, ao mesmo tempo, as ciências, as humanidades e preparando para o trabalho. $[\ldots]$

A outra razão para a volta do curso integrado é a predisposição das escolas técnicas federais para ter alunos academicamente muito fortes, como os tinham antes. Tal como não havia bons dados antes, não os há agora. Mas tudo indica que as escolas não se conformaram com a queda de nível acadêmico inerente à separação, pois os cursos técnicos, sem o acadêmico junto, se teriam tornado menos atraentes para os alunos academicamente mais fortes.

(CASTRO, 2008, p. 122).

Este último argumento de Castro, sem base científica como o mesmo admite, referese à afirmação de que as escolas da RFEPT seriam elitistas e prepararem para o ensino superior quando em realidade deveriam preparar para o mundo imediato do trabalho, um argumento que desconsidera a formação do trabalhador para sua transformação em dirigente e da sociedade capitalista desigual, mantendo sua dualidade estrutural. $\mathrm{O}$ autor também parece sugerir que a sociedade é naturalmente dividia entre os mais aptos, destinados à formação acadêmica e os menos aptos, destinados à formação profissional e ao mercado de trabalho, e proporcionar uma educação que integre a formação geral e técnica seria um desperdício de dinheiro. O autor diz que ao optar pela formação profissional no ensino médio integrada ao técnico: "[...] nem medimos corretamente o que sai no fim da linha, nem barramos a saída para os que não atingem um certo limiar de domínio dos conteúdos ensinados. Menos ainda, podemos avaliar o prejuízo resultante de tentar ensinar um mesmo currículo para alunos com aptidões e preparo muito diferentes." (CASTRO, 2008, p. 123).

Para Vieira (2014), o formato final do Decreto 5.154 de 2004 (BRASIL, 2004) e sua inserção no plano da Lei de Diretrizes e Bases da Educação - LDB- demonstram tanto o embate de forças ideológicas e políticas presentes neste momento histórico do governo federal, dos intelectuais brasileiros marxistas de esquerda e neoliberais associados ao governo anterior, como o receio de que um novo governo pudesse retroceder nos ganhos já adquiridos. Assim, ainda na segunda metade dos anos 2000, a Lei № 11.741/2008 (BRASIL, 2008a) modifica os quatro artigos da LDB que tratavam da educação profissional, mudando o vocabulário para educação profissional e tecnológica, e criando uma nova seção e novos artigos, detalhando a oferta de ensino técnico associado ao ensino médio, incorporando à LDB o texto do Decreto n. 5.154/2004 (BRASIL, 2004). A lei também dispõe sobre os tipos 
de cursos que a educação profissional e tecnológica abrangerá: de formação inicial e continuada ou qualificação profissional, técnica de nível médio e tecnológica de graduação e pós-graduação. Sobre o ensino técnico de nível médio, mantêm-se a articulação à formação geral de forma integrada (matrícula única, na mesma escola) ou concomitante (matrículas distintas, na mesma ou em outra instituição, para quem ingressa ou já cursa o ensino médio) ou ainda na forma subsequente, para aqueles que já cursaram o ensino médio. Em 2012 foram definidas novas Diretrizes Curriculares Nacionais para a Educação Profissional Técnica de Nível Médio (BRASIL, 2012a), tendo em conta as modificações legais ocorridas no período. Nas Diretrizes Curriculares Nacionais para a Educação Profissional de Nível Técnico de 1999 (BRASIL, 1999), o termo competência surge 69 vezes, enquanto que nas novas Diretrizes Curriculares Nacionais para a Educação Profissional Técnica de Nível Médio de 2012 (BRASIL, 2012a), o termo competência continua sendo usado, mas aparece apenas 8 vezes.

Gráfico 2 - Matrícula regular no ensino médio técnico integrado, concomitante e subsequente por dependência administrativa no Brasil em 2015

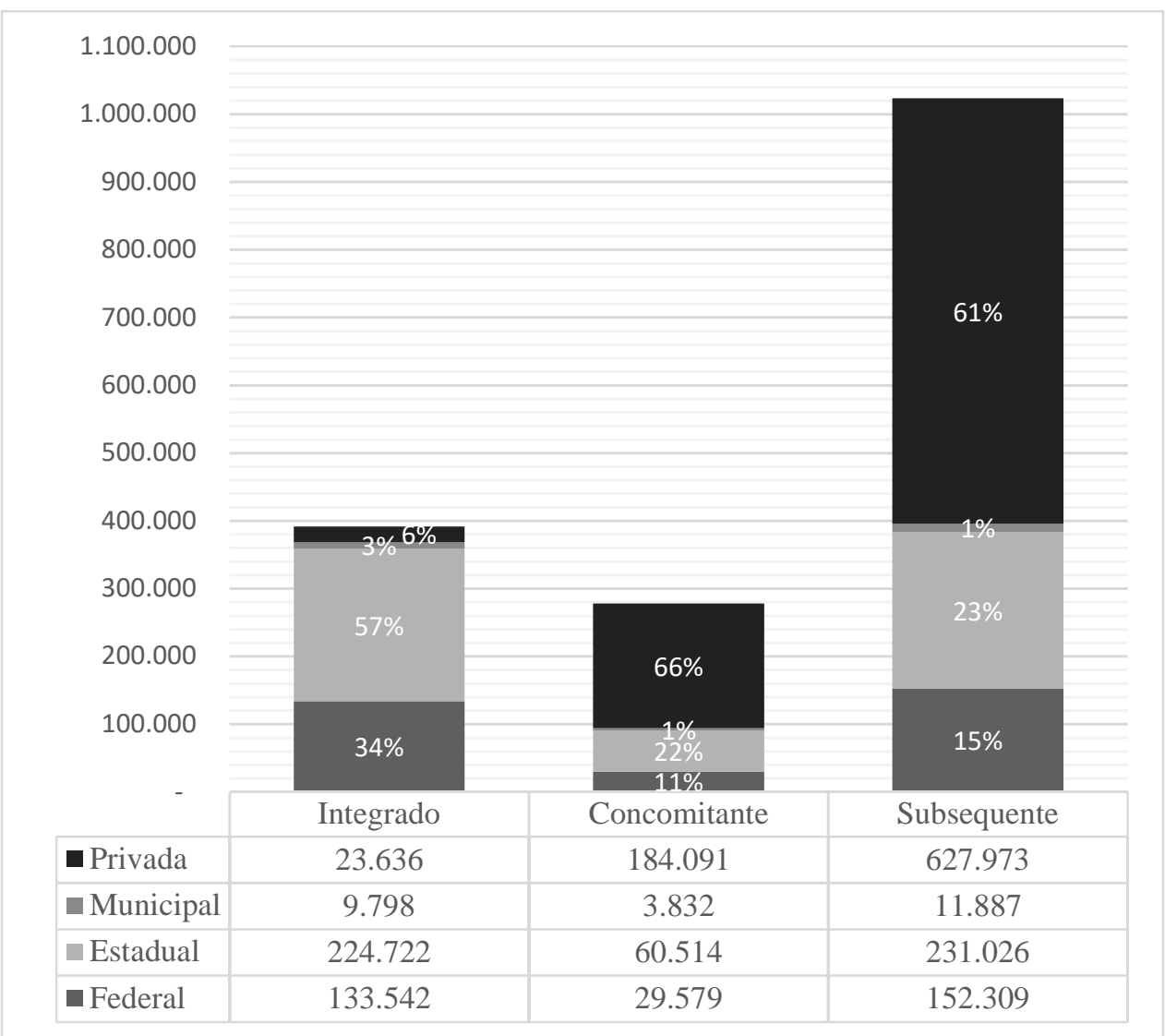

Fonte: Sinopse Estatísticas da Educação Básica (INEP, 2016). 


\section{Programas voltados para a educação profissional}

Foram várias as iniciativas públicas entre 2003 e 2015 para fomentar a educação profissional nas diversas redes (SILVA; ALMEIDA; STROKOVA, 2015; AUGUSTO SILVA, 2013; AMORIM, 2013), com destaque no ensino médio técnico para:

A Rede Nacional de Certificação Profissional e Formação Inicial e Continuada- Rede CERTIFIC, criada em 2007, que, dentre outras funções, elabora padrões nacionais de certificação profissional para serem utilizados obrigatoriamente pelas instituições de Educação Profissional e Tecnológica - EPT - do sistema federal de ensino e das redes públicas estaduais, quando em processos de certificação.

I. O Plano de Desenvolvimento da Educação - PDE - que consiste em uma política pública que agrega um conjunto de mais de 40 programas organizados em torno de quatro eixos, incluindo educação profissional ${ }^{3}$. O seu propósito é elevar o nível da educação brasileira aos patamares dos países desenvolvidos, com prazo para execução até 2022, tendo sido lançado em 2007. Para ser implementado, o PDE precisa ganhar a adesão de estados e municípios, por meio de termo de adesão voluntária a um plano de metas de qualidade. O seu regime de colaboração entre União, estados, Distrito Federal - DF - e municípios coloca à disposição instrumentos de avaliação e de implementação de políticas de melhoria da qualidade da educação. Dividido em eixos - educação básica, superior, profissional e alfabetização - o PDE apresenta uma visão sistêmica, com níveis, modalidades e etapas da educação como elos de uma cadeia que se deve reforçar mutuamente.

II. O Programa Ensino Médio Inovador, oferece apoio aos estados e DF, que mediante parcerias com os colégios de aplicação (vinculados à Universidades Federais), o Colégio Pedro II/RJ, os Institutos Federais de Educação, Ciência e Tecnologia- IFs- e o Sistema $S^{4}$, incentiva a organização de currículos para o ensino médio que procurem superar as dicotomias entre humanismo e tecnologia e entre a formação teórica geral e técnica-instrumental. Apesar de se articular com a educação profissional, o Programa tem sua administração central na Secretaria da Educação Básica / Ministério da Educação - SEB/MEC.

\footnotetext{
${ }^{3}$ Especificamente, sobre a educação profissional, contempla as Instituições Federais de Educação, Ciência e Tecnologia IFETs- na articulação entre educação, território e desenvolvimento e a perspectiva de integração entre o ensino médio e a educação profissional, o Programa Nacional de Integração da Educação Profissional com a Educação Básica, na modalidade de Educação de Jovens e Adultos - PROEJA e o Programa Nacional de Inclusão de Jovens: Educação, Qualificação e Ação Comunitária- PROJOVEM.

${ }^{4}$ Nos anos 1940 se dá início ao que é hoje o "Sistema S", como um sistema privado, gerenciado pelo setor patronal, de formação da força de trabalho ligado às demandas produtivos, para atender o processo de desenvolvimento do país na era Vargas, com subvenção e tutoria estatal. $\mathrm{Na}$ atualidade, o Sistema S é o principal ente privado de formação profissional brasileiro e recebe repasses de receitas proveniente de impostos para fins de capacitação e formação da mão de obra.
} 
III. O Programa Nacional de Integração da Educação Profissional com a Educação Básica, na modalidade de Educação de Jovens e Adultos -PROEJA -, que pelo Decreto $n^{\circ}$ 5.840/2006 (BRASIL, 2006) obriga a sua oferta pelas instituições federais de educação profissional, pelas públicas estaduais e municipais e pelo Sistema $\mathrm{S}$.

IV. O Programa Nacional de Acesso ao Ensino Técnico e Emprego - PRONATEC, criado em 2011 pela Lei oㅜ 12.513 (BRASIL, 2011a), e em parceria com outros Ministérios para identificação de demandas de formação técnica, ofertou 8,8 milhões de vagas em um intervalo de 4 anos (ainda que ofertando o técnico de nível médio, a grande maioria era de cursos de Formação Inicial e Continuada -FIC- de curta duração) e gastou cerca de $0,06 \%$ do PIB, investidos majoritariamente no setor privado, com destaque para o Sistema S; ainda que também tenha investido nas redes federais, estaduais, distrital e municipais de educação profissional e tecnológica.

O referido programa tem como principal propósito expandir, interiorizar e democratizar a oferta de cursos de educação profissional e tecnológica para a população brasileira. Para cumprir tal propósito, prevê um conjunto de subprogramas, projetos e ações de assistência técnica e financeira entre os quais se destacam: a) a expansão da Rede Federal de Educação Profissional Tecnológica (EPT); b) o fomento às redes estaduais de EPT por intermédio do Brasil Profissionalizado; c) a consolidação da Rede e-Tec; d) a criação da Bolsa - Formação; e) a criação do Fundo de Financiamento ao Estudante do Ensino Técnico - FIES técnico5. (AMORIM, 2013, p. 64).

Identifica-se que o PRONATEC será um "programa guarda-chuva" que abriga diversas iniciativas, muitas das quais já estavam em andamento antes de 2011. De forma geral o PRONATEC ficará conhecido principalmente pela ação BolsaFormação.

A Bolsa -Formação é apresentada como a principal novidade do Pronatec. Possibilitará a trabalhadores, estudantes e pessoas em vulnerabilidade social o acesso gratuito a cursos presenciais técnicos de Formação Inicial e Continuada, bem como alimentação, transporte e todos materiais escolares necessários. Os cursos serão ofertados por escolas de Educação Profissional da Rede Federal e Estadual, bem como por unidades de serviços nacionais de aprendizagem (AMORIM, 2013, p. 64).

V. A Rede e-Tec Brasil, conforme Decreto nํ⒍301/ 2007 (BRASIL, 2007b) e Decreto oㅜ 7.589/2011 (BRASIL, 2011b), baseada no ensino a distância, que oferece cursos na

\footnotetext{
${ }^{5}$ Direcionado ao financiamento a estudantes regularmente matriculados em cursos superiores não gratuitos e com avaliação positiva nos processos conduzidos pelo Ministério da Educação.
} 
modalidade EPT gratuitos, realizados pelas escolas de ensino técnico (municipais, estaduais, federais) e universidades.

VI. O Brasil Profissionalizado, instituído pelo Decreto n. 6.302/2007 (BRASIL, 2007c), que visa fortalecer a oferta da formação técnica de nível médio por meio das redes estaduais, tem por objetivo estimular o ensino médio integrado à educação profissional, enfatizando a educação científica e humanística, por meio da articulação entre formação geral e educação profissional no contexto dos arranjos produtivos e das vocações locais e regionais. É o sucessor do Programa de Reforma da Educação Profissional - PROEP, agora com financiamento exclusivamente nacional (VIEIRA, 2014).

VII. O plano de expansão da rede federal de educação profissional. Destaca-se nesse sentido a Lei 11.195 de 2005 (BRASIL, 2005), que permite ao governo federal o protagonismo da expansão desta modalidade de ensino, ao contrário do governo anterior que centrava os investimentos pelos estados. Esta lei altera o dispositivo legal dos anos 1990 que impedia a rede federal de se expandir sem o estabelecimento de parcerias com outras esferas administrativas (BRASIL, 1998). O financiamento e manutenção dos Institutos Federais têm com fonte orçamentária o governo central.

Com relação a este último, de 1909 a 2002 foram construídas 140 escolas técnicas federais no país, entre 2003 e 2010 o MEC construiu 214 escolas técnicas e em 2014, a rede federal de escolas técnicas passou a contar com um total de 562 unidades em 512 Municípios e presença em todos os estados, com investimentos de R $\$ 678$ milhões apenas em 2014 (BRASIL, 2017).

Com a criação dos Institutos Federais, a função programática Desenvolvimento da Educação Profissional e Tecnológica, que era da ordem de $R \$ 1,2$ bilhão, em 2003, passou para $R \$ 2,3$ bilhões, em 2009, e atingiu na Lei Orçamentária Anual (LOA) de 2012, a marca de $R \$ 5.040$ bilhões. A participação da educação profissional no orçamento do MEC em 2012 aproxima-se dos 8\% do total do Ministério. Em 2003, essa participação era de $6 \%$, representando um crescimento de 30\%. (PACHECO, 2012, p. 14).

Em 2005 o novo programa de expansão da rede federal criou 60 novas unidades sob a forma de Centro Federal de Educação Tecnológica - CEFET- ou unidades de ensino descentralizadas (VIEIRA, 2014). Também em 2005 o CEFET Paraná vira Universidade Tecnológica pela Lei n. 11.184/2005. O CEFET Minas e o CEFET Rio também tentaram 
virar universidades tecnológicas ${ }^{6}$, mas sem sucesso, mantendo-se como CEFETs até os dias atuais. Para Amorim (2013, p. 142) o "formato da Universidade Tecnológica foi recusado pelo governo pois, entre outros aspectos, negava a oferta de cursos de nível médio técnico e, assim, não contribuía para manter a "verticalização" (supostamente um bloco tecnológico inteiro de educação, em todos os níveis)".

Segundo Pacheco (2012, p. 13), Secretário da Secretaria de Educação Profissional e Tecnológica / Ministério da Educação - SETEC/MEC à época, a primeira fase desse processo de expansão implantou escolas federais de formação profissional e tecnológica em vários estados, com o intuito de fornecer cursos articulados com as potencialidades locais de geração de trabalho. Segundo a SETEC/MEC (BRASIL, 2013c, p. 11), a expansão ocorre "não apenas para a inclusão social e produtiva, mas também para o aumento da produtividade e competitividade da economia brasileira".

No contexto da expansão da RFEPT, a Lei no 11.892/2008 (BRASIL, 2008b) demarca uma nova etapa para a educação profissional no país, ao criar os IFs, que são instituições de educação superior, básica e profissional, pluricurriculares e multicampi, especializadas na oferta de educação profissional e tecnológica.

No bojo da expansão da rede federal de EPT, em termos de contratações ${ }^{7}$, os IFs saltaram de 19.257 docentes efetivos (sem contar as contratações temporárias), em 2010, para 34.836 em abril de 2016, um aumento de aproximadamente $81 \%$, e de 16.748 técnicos administrativos em educação, em 2010, para 31.295 em abril de 2016, um aumento de aproximadamente $87 \%$. A política de contratação e os planos de carreira enfatizavam a exigência de titulação de nível de pós-graduação para os docentes da RFEPT, o que para alguns analistas termina por tornar a formação ofertada "bacharelesca" em contraposição ao que seria uma formação técnica, alinhada à demanda produtiva e à prática, porém não foram encontrados estudos que confirmem essa hipótese de que a maior titulação influenciasse negativamente no tipo de formação ofertada. Ao contrário, os estudos demonstram que a qualidade da educação de nível médio técnico ofertada pelos IFs se destaca nos exames nacionais (SILVA FILHO; MORAES, 2017) e em relação ao atendimento das demandas regionais produtivas (ALKMIM, 2015).

Esta expansão física vem acompanhada pela contratação maciça de novos professores, cujos vencimentos foram equiparados ao do corpo docente das Universidades Federais. Em termos financeiros explorando os valores expressos nas Leis Orçamentárias Anuais (LOA), verifica-se que o montante

\footnotetext{
${ }^{6}$ Ainda que existem muitas controvérsias sobre o tema, Amorim (2013) sintetiza a diferença entre universidade tecnológica e universidade "comum", como atrelada ao foco que a primeira daria a um conhecimento de caráter mais prático e aplicado, e que a segunda daria a um conhecimento mais "abstrato, enciclopédico".

7 Dados facilitados pela Coordenação Geral de Desenvolvimento de Pessoas da Rede, em base a consulta ao Sistema Integrado de Administração de Pessoal - SIAPE, em 25/01/2017.
} 
de recursos disponibilizados à REDE experimentou um acréscimo superior a $800 \%$ nesta década, beirando a inédita marca dos $\mathrm{R} \$ 10$ bilhões em 2014 . (MORAES, 2016, p. 3).

Para Moraes (2016) os IFs foram a principal aposta educacional do Estado brasileiro nas últimas décadas, concebidos por inspiração desenvolvimentista, que enxerga na EPT, e em especial na oferta de cursos técnicos, um poderoso motor de desenvolvimento para a sociedade brasileira. Conforme Amorim (2013, p. 22) o novo modelo de educação profissional implantado no governo federal após as eleições de 2003, pauta-se na verticalidade da oferta de educação profissional e tecnológica, na articulação com o ensino regular, no aumento da escolaridade do trabalhador, na interação com o mundo do trabalho, e no apoio à escola pública. No entanto, esses ideais presentes nos discursos oficiais do governo, encontram embates ideológicos e políticos para sua implementação.

A Lei no 11.892/2008 (BRASIL, 2008b) e o Plano Nacional de Educação -PNE2014-2024, Lei no 13.055/14, (BRASIL, 2014) estabelecem prioridade para a oferta de educação profissional técnica de nível médio ao determinarem, respectivamente, que $50 \%$ das vagas das novas instituições devem ser para esse nível, prioritariamente de oferta integrada, e que, em sua Meta 11, se tripliquem no Brasil as matrículas da educação profissional técnica de nível médio e, ainda, que, destas, 50\% estejam na educação pública. O PNE 2014-2024 (BRASIL, 2014), avaliam Duarte e Santos (2015), define para educação diretrizes, objetivos, metas e estratégias de implementação, assegura a manutenção e desenvolvimento do ensino por meio de ações integradas dos poderes públicos das diferentes esferas federativas, e contém dispositivos normativos que instituem mecanismos de regulação por desempenho do sistema nacional, com abrangência e funcionamento territorial uniforme. A Lei do plano decenal ${ }^{8}$ dispõe quanto aos procedimentos de assistência técnica e financeira da União, mediante ênfase em políticas e programas distributivos, por sua vez monitorados por um sistema nacional de avaliação (ARAÚJO; 2015).

A Lei que cria os IFs também reserva $20 \%$ das vagas para os cursos de licenciatura, programas especiais de formação pedagógica com vistas a formação de professores para a educação básica com ênfase nas áreas de ciências, matemática e educação profissional. Segundo a SETEC/MEC (BRASIL, 2013), de 2008 a 2012 o maior aumento de matrículas na

\footnotetext{
${ }^{8}$ O primeiro Plano Nacional de Educação (BRASIL, 2001) no âmbito da redemocratização do país foi fruto de conferências que tiveram lugar nos anos 1990, constituindo novos espaços institucionais de deliberação. Para Duarte e Santos (2014a), os novos atores a partir dos anos 1986, produziram rupturas com as concepções autoritárias de planejamento, desagregando o planejamento tecnocrático mais usual no país e incorporando novas intermediações entre Estado e Sociedade. O I e II Congressos Nacionais de Educação e o projeto de Lei da "Sociedade Brasileira" -projeto de Lei 8.035-, que foi apoiado e organizado por entidades majoritariamente sindicais e por organizações de profissionais da educação e prefeituras do Partido dos Trabalhadores, foram, na percepção de Duarte e Santos (2014a), exemplos de planejamento e gestão pública "democrática-participativa", sendo práticas discursivas que se deslocam da disputa partidária. Porém, apesar desse processo, a Lei 10.172 de 9/01/2001, que foi produzida por expertos em educação, mas alberga a existência de proposições antagônicas de planejamento que orientam as práticas discursivas, é que institui o Plano Nacional de Educação de 2001 a 2011 (BRASIL, 2001), o qual na concepção de Duarte e Santos (2014b) é um projeto de um sistema nacional de educação como política de Estado. O processo de discussão do PNE refletiu uma explosão das diferenças e desconstrução do imaginário de um tratamento uniforme para nação.
} 
rede federal de escolas técnicas ocorreu no ensino médio técnico: de 34 mil para 453,7 mil matrículas. Alguns analistas acreditavam que a criação dos IFs geraria uma migração da RFEPT para cursos de nível superior e pós-graduação. Para Moraes (2016), a nova identidade dos IFs passava pelo dilema entre a tradição das escolas técnicas (com uma tradicional oferta de nível médio técnico), pautadas pela técnica e pela inclusão, mas também pelo desprestigio econômico, ou o caminho da inovação, marcado pelas luzes da ciência e pelas possibilidades de ascensão social (identificada com a oferta em graduação e pós-graduação). No entanto, Andrade (2014), por meio de análise quantitativa com base nos dados disponíveis no Sistema Nacional de Informações da Educação Profissional e Tecnológica - SISTEC, concluiu que não houve decréscimo na oferta de cursos técnicos mediante a ampliação de cursos superiores a partir de 2008. A autora conclui que quanto maior o número de matrículas nos cursos de graduação, maior também será a oferta dos cursos técnicos. Desse modo, o aumento dos cursos de graduação não inibe a oferta de cursos técnicos.

\begin{abstract}
De forma mais empírica, esta pesquisa traz importantes elementos, que por um lado, retiram a ênfase de que a oferta de educação superior, nos Institutos, seria predominante e danosa à oferta de curso técnicos e caminha mais na direção que reforça aspectos do peso de sua historicidade e tradição na oferta de cursos técnicos. Existe uma influência mútua entre a oferta de cursos técnicos e de graduação, com a predominância de seu matiz técnico. (ANDRADE, 2014, p. 186).
\end{abstract}

Para Vieira (2014) o investimento prioritário na educação profissional técnica de nível médio integrada, também fomentada no Brasil Profissionalizado, representou uma aposta inicial do governo Lula em um modelo que integrasse tanto a formação humanística como tecnológica, com promessa de inclusão social e não apenas de inserção profissional, mas que na prática enfrentou resistência para ser implementado pelos governos locais. Como relata Vieira (2014), os gestores estaduais de educação, protestaram no MEC, junto ao então ministro Haddad, em contra à exigência inicial do Brasil Profissionalizado de financiar apenas o modelo de formação profissional técnica de nível médio integrada, dado seu alto custo, dificuldades administrativas e de articulação das redes, reivindicações estas que foram aceitas, passando a ser considerado o financiamento para qualquer das formas de articulação do ensino médio à formação técnica. Diante da pouca adesão e apoio às suas proposições, o MEC viu desmoronar seu projeto de expansão nas distintas redes de um modelo de escola que oferecesse o ensino médio com currículo integrado à formação profissional (VIEIRA, 2014).

Mesmo em relação à formação profissional de nível médio técnico integrada nos IFs, constata-se, por meio de pesquisas acadêmicas, que as formações geral e técnica não 
chegam realmente a dialogar, simplesmente sobrepõem-se os dois currículos, comprometendo uma formação realmente integral (OTRANTO, 2011). Na prática, a matrícula é integrada, mas o ensino não (AMORIM, 2013, p. 213-214).

Os IFs representam uma nova institucionalidade adquirida com a lei (AMORIM, 2013), mas remonta a uma história de longa data da educação profissional no país. Alguns IFs surgem a partir da fusão, por exemplo, com escolas de aprendizes artífices criadas em 1909 que eram dirigidas aos desvalidos da sorte, filhos de operários entre 10 e 13 anos, com o intuito de ocupar o tempo livre evitando a marginalidade e a ociosidade. Os IFs foram criados pela transformação ou integração de CEFETs, escolas técnicas e agrotécnicas federais ou escolas técnicas vinculadas às Universidades Federais. Além dos IFs, ainda compõem a rede federal atualmente remanescentes CEFETs, Minas e Rio, (com oferta a nível de qualificação, ensino médio, superior e pós-graduação) e 24 das 32 escolas técnicas vinculadas a Universidades, que não se transformaram em IFs, a Universidade Tecnológica do Paraná (antigo CEFET Paraná, transformado na primeira universidade tecnológica do país em 2005) e o Colégio Pedro II no Rio de Janeiro. Observa-se que com a criação dos IFs surge em 2009 o Conselho Nacional das Instituições da Rede Federal de Educação Profissional, Científica e Tecnológica (CONIF), que congrega os Reitores dos mesmos, sendo uma instância de discussão, proposição e promoção de políticas de desenvolvimento da educação profissional. A RFEPT e, nesta, os IFs distam de ser homogêneos em sua institucionalidade. As escolas que compõem a RFEPT já foram denominadas: Escola de Aprendizes Artífices, Liceu Industrial, Escola Industrial e Técnica, Escola Técnica Federal, Centro Federal de Educação Tecnológica, Universidade Tecnológica Federal, Instituto Federal de Educação Ciência e Tecnologia; isso sem contar com os Institutos Federais que não derivam das 19 primeiras escolas, tais como os derivados das Escolas Agrotécnicas, com base no modelo escola fazenda.

Nos termos da Lei oํ 11.892 (BRASIL, 2008b), os Institutos Federais são autarquias que possuem autonomia administrativa e didático-pedagógica. Ainda que se constituam como autarquias, os IFs têm uma institucionalidade alinhada e submetida às diretrizes do governo central.

Como o limite da autonomia das autarquias é definido pelos fins para os quais elas são criadas, a lei estabelece referenciais de atendimento em diferentes ofertas educativas, explicitando a atuação mínima requerida nas diferentes faces do serviço público prestado pela instituição. Tal ação tem como objetivo resguardar a proporcionalidade da oferta entre os diferentes cursos a fim de garantir a consecução de um projeto político educacional. (SILVA et al, 2009, p. 46).

A proposta dos IFs exposta nos documentos publicados pelo MEC e pelos gestores presentes na SETEC/MEC à época (SILVA et al, 2009; PACHECO, 2012) exprimem 
preocupação com a justiça social e com a competitividade e o desenvolvimento econômico. Longe de ser apenas uma política de expansão, trata-se de trazer ao embate na formulação e implementação de políticas públicas princípios ideológicos e discursivos ligados à assistência social e ao desenvolvimento econômico do país, que estiveram historicamente à frente dos debates sobre a educação profissional. Os argumentos ao redor da criação dos IFs, unem a promoção da educação profissional e a inclusão social, dentro de uma lógica econômica neodesenvolvimentista (REIS JUNIOR, 2017), que encontra nos limites do capital sua possibilidade de concretização.

O foco principal seria o mercado (FERRETI; 2010), pois há um estreito vínculo dos IF com o mercado (OTRANTO; 2010). Isso se mostra, evidente, em face das políticas de incentivo ao crescimento do país que têm início na gestão de Lula e se ampliam no governo Dilma - orientadas por um projeto de fortalecimento de todos os setores da economia, de valorização da indústria nacional e do aumento da competitividade brasileira. (AMORIM, 2013, p. 73).

A luta pela hegemonia dos sentidos da educação profissional no Brasil irá também passar pela construção de fóruns de debates com os diferentes setores da sociedade e atores sociais envolvidos com a definição e implementação das políticas. Está presente no período entre 2003 e 2010 a ideia de se discutir coletivamente as propostas para a educação profissional, como um esforço do MEC em promover oportunidades para o debate e a definição de um projeto nacional pensado por diversos segmentos que compõem a modalidade no país, a exemplo da I Conferência Nacional de Educação Profissional e Tecnológica (CONFETEC), promovida em 2007, com 10 mil participantes (AMORIM, 2013). "Buscou se validar, na disputa por hegemonia, por meio de seminários (2003), conferências (2006, 2010), fóruns $(2005,2006,2007)$, disputas internas no âmbito do governo [...]" (VIEIRA, 2014, p. 175-176). Já a partir de 2011, ainda conforme Vieira (2014), esses debates e construções coletivas das políticas se tornam cada vez mais escassos, passando essas a serem elaboradas nos espaços burocrático-governamentais, com pouca ou nenhuma participação de outros setores. Uma das instâncias que foram ganhando maior relevância com o passar dos anos de governo, no que se refere à avaliação das políticas públicas nacionais para a educação profissional, foi o Tribunal de Contas da União - TCU.

Com a justificativa dos altos investimentos nos últimos anos na Rede Federal de Educação Técnica e o seu caráter estratégico para o desenvolvimento do país, o TCU fez auditoria (TCU 026.062 / 2011-9) sobre as ações de estruturação e expansão da educação profissional, com ênfase na atuação dos IFs. Na análise do Tribunal de Contas da União TCU- (BRASIL, 2012b), o investimento na Rede Federal a partir de 2003 foi motivado pelo crescimento econômico do Brasil que pressionou a demanda por mão de obra qualificada, e 
a preocupação com a diminuição das desigualdades regionais que impulsionou uma política de interiorização da rede federal para induzir o desenvolvimento das microrregiões por meio da melhoria da produtividade dos trabalhadores aptos a atuarem em diversos segmentos da economia e a participarem do mundo científico e tecnológico. Porém, segundo o TCU (BRASIL, 2012b), na prática há risco de baixa eficácia dessa medida, não só por questões administrativas (dificuldades com os tramites burocráticos, insegurança jurídica na interação iniciativa privada e pública), mas também dado aos níveis sociais e econômicos das regiões dos campi e a ausência de outras intervenções governamentais, o que gera o risco de tornar a presença dos Institutos pouco eficaz na promoção do desenvolvimento regional. O peso relativo do setor público nas economias locais coloca em risco a intenção inicial da proposta, já que não se encontra uma estrutura produtiva suficientemente dinâmica. O TCU destaca princípios econômicos em sua análise, desconsiderando a importância de se levar educação profissional à essas regiões e populações.

O elenco de políticas de educação profissional desenvolvidas no governo Lula indica que essa modalidade educativa é tomada como uma prioridade; ênfase que irá continuar no governo Dilma, como pode ser percebido pelas metas contidas no novo PNE e com a continuidade de determinadas políticas como a expansão da rede federal, ainda que também se percebam novos contornos nessa política de aposta na EPT, como o PRONATEC.

A partir de 2011, com o PRONATEC abriu-se para o Sistema $S$ e escolas privadas a possiblidade de transferência de recursos públicos para o atendimento da demanda por capacitação profissional. Se educação é mercadoria, não importa quem a oferta, porque não é mais parte de um projeto de Estado educador. Para Viera (2014) o PRONATEC implantado a partir de 2011 e com fortes investimentos até 2015 -, ativa lógicas de quase mercado no setor público. Os serviços públicos de interesse social guardam um grande potencial para a reprodução e acumulação do capital, explicito pela configuração no papel do Estado brasileiro, que está subordinado aos processos de transnacionalização das políticas para a educação profissional, sob o direcionamento do Banco Mundial e outros organismos internacionais. Embora não de forma direta pela simples incorporação, subordina-se a política nacional para a educação profissional, principalmente no que se refere ao papel do Estado.

Há um aspecto contraditório na oferta de EPT quando se preconiza que os IFs devem investir preferencialmente na formação técnica de nível médio integrada, mas, em paralelo, o governo federal investe pesadamente na formação aligeirada de trabalhadores por meio do PRONATEC, ao qual os IFs aderiram por meio da remuneração extra adotada, mas que também sobrecarrega o trabalho do professor. Percebe-se no PRONATEC a privatização da educação profissional com o reforço do sistema $S$ em detrimento de um 
reforço das instituições públicas de ensino e da formação técnica de nível médio integrada, representando uma contradição nas políticas.

\section{Considerações Finais}

Neste trabalho discutiram-se as mais recentes políticas governamentais destinadas à educação profissional no Brasil, em especial ao ensino médio técnico. A partir do novo governo de esquerda que sobe ao governo federal no Brasil em 2003, passou-se a investir no ensino profissionalizante, mas essas políticas encontram diversos embates para se estruturarem albergando ainda contradições internas como reflexo das disputas pela direção no Estado e na sociedade, vigorando a organização dualista, com a existência de um bloco de ensino profissionalizante em paralelo destinado à formação dos trabalhadores, e os desígnios neoliberais, com forte influência dos organismos internacionais e a transferência de recursos públicos para mãos privadas.

\section{Agradecimentos}

Ao CNPq pelo financiamento parcial da pesquisa, por meio do Programa de Bolsa de Doutorado Sanduíche no País.

\section{Referências}

ALKMIM, G. V. Empregabilidade dos egressos dos cursos superiores de tecnologia em diferentes regiões do estado de Minas Gerais: o caso do curso de análise e desenvolvimento de sistemas. 2015. 238 f. Tese (Doutorado em Educação) - Faculdade de Educação, Universidade Federal de Minas Gerais, Belo Horizonte, 2015.

AMORIM, M. M. T. A organização dos Institutos Federais de Educação, Ciência e Tecnologia no conjunto da educação profissional brasileira. 2013. 245 f. Tese (Doutorado em Educação) - Faculdade de Educação, Universidade Federal de Minas Gerais, Belo Horizonte, 2013.

ANDRADE, A. F. B. Os Institutos Federais de Educação, Ciência e Tecnologia: uma análise de sua institucionalidade. 2014. 209 p. Tese (Doutorado em Educação) - Faculdade de Educação, Universidade de Brasília, Brasília, 2014.

ARAÚJO, J. N. Relações intergovernamentais e a gestão municipal da educação escolar: um estudo da implementação de programas e projetos federais em municípios do estado da Bahia. 2015. 166 f. Tese (Doutorado em Educação) - Faculdade de Educação, Universidade Federal de Minas Gerais, Belo Horizonte, 2015. 
AUGUSTO SILVA, W. Fatores de permanência e evasão no Programa de Educação Profissional de Minas Gerais (PEP/MG):2007 A 2010. 2013. 221 f. Tese (Doutorado em Educação) - Faculdade de Educação, Universidade Federal de Minas Gerais, Belo Horizonte, 2013.

BRASIL. Decreto № 2.208, de 17 de abril de 1997. Regulamenta o $\S^{\circ}$ do art. 36 e os artigos 39 a 42 da lei 9.394, de 20 de dezembro de 1996, que estabelece as diretrizes e bases da educação nacional. Diário Oficial da União, Brasília, 18 abr. 1997. Disponível em: <http://www.planalto.gov.br/ccivil_03/decreto/d2208.htm>. Acesso em: 02 nov. 2017.

BRASIL. Decreto № 5.154, de 23 de julho de 2004. Regulamenta o $§ 20$ do art. 36 e os arts. 39 a 41 da Lei № 9.394, de 20 de dezembro de 1996, que estabelece as diretrizes e bases da educação nacional, e dá outras providências. Diário Oficial da União, Brasília, 26 jul. 2004.

Disponível

em:

<http://www.planalto.gov.br/ccivil_03/_ato2004-2006/2004/decreto/d5154.htm>. Acesso em: 12 dez. 2017.

BRASIL. Decreto nํ⒌840, de 13 de Julho de 2006. Institui, no âmbito federal, o Programa Nacional de Integração da Educação Profissional com a Educação Básica na Modalidade de Educação de Jovens e Adultos - PROEJA, e dá outras providências. Diário Oficial da União, Brasília, 14 Jul. 2006. Disponível em: <http://www.planalto.gov.br/ccivil_03/_ato20042006/2006/decreto/d5840.htm>. Acesso em: 22 dez. 2017.

BRASIL. Decreto no 6.301, de 12 de dezembro de 2007. Institui o sistema escola técnica aberta do Brasil - e-tec Brasil. Diário Oficial da União, Brasília, 13 dez. 2007b. Disponível em: <http://www.planalto.gov.br/ccivil_03/_ato2007-2010/2007/decreto/d6301.htm>. Acesso em: 12 dez. 2017.

BRASIL. Decreto no 6.302, de 12 de dezembro de 2007. Institui o Programa Brasil Profissionalizado. Diário Oficial da União, Brasília, 13 dez. 2007c. Disponível em: <http://www.planalto.gov.br/ccivil_03/_ato2007-2010/2007/decreto/d6302.htm>Acesso em: 02 nov. 2017.

BRASIL. Decreto no 7.589, de 26 de outubro de 2011. Institui a rede e-tec Brasil. Diário Oficial da União, Brasília, 27 out. 2011b. Disponível em: <http://www.planalto.gov.br/ccivil_03/_ato2011-2014/2011/decreto/d7589.htm>. Acesso em: 12 dez. 2017.

BRASIL. Lei no 11.195 de 18 de novembro de 2005. Dá nova redação ao $\S 5^{\circ}$ do art. $3^{\circ}$ da Lei $n^{\circ} 8.948$, de 8 de dezembro de 1994. Diário Oficial da União, Brasília, 18 nov. 2005a. (edição extra).

BRASIL. Lei no 11.892 de 29 de dezembro de 2008. Institui a Rede Federal de Educação Profissional, Científica e Tecnológica, cria os Institutos Federais de Educação, Ciência e Tecnologia, e dá outras providências. Diário Oficial da União, Brasília, 30 dez. 2008b. 
BRASIL. Lei $n^{\circ} 12.513$ de 26 de outubro 2011. Institui o Programa Nacional de Acesso ao Ensino Técnico e Emprego (Pronatec); altera as Leis $n^{\circ}$ 7.998, de 11 de janeiro de 1990, que regula o Programa do Seguro-Desemprego, o Abono Salarial e institui o Fundo de Amparo ao Trabalhador (FAT), n 8.212, de 24 de julho de 1991, que dispõe sobre a organização da Seguridade Social e institui Plano de Custeio, $n^{\circ}$ 10.260, de 12 de julho de 2001, que dispõe sobre o Fundo de Financiamento ao Estudante do Ensino Superior, e $n^{\circ} 11.129$, de 30 de junho de 2005, que institui o Programa Nacional de Inclusão de Jovens (ProJovem); e dá outras providências. Diário Oficial da União, Brasília, 27 out. 2011a.

BRASIL. Lei no 9.649 de 27 de maio de 1998. Dispõe sobre a organização da Presidência da República e dos Ministérios, e dá outras providências. Diário Oficial da União, Brasília, 28 maio 1998.

BRASIL. Lei no 11.494 de 20 de junho de 2007. Regulamenta o Fundo de Manutenção e Desenvolvimento da Educação Básica e de Valorização dos Profissionais da Educação FUNDEB. Diário Oficial da União, Brasília, 21 jun. 2007a. Disponível em: <http://www.planalto.gov.br/ccivil_03/_ato2007-2010/2007/lei/111494.htm>. Acesso em: 12 dez. 2017.

BRASIL. Lei no 13.055 de 2 de junho de 2014. Aprova o Plano Nacional de Educação - PNE e dá outras providências. Diário Oficial da União, Brasília, 26 jun. 2014. Disponível em: <http://www.planalto.gov.br/ccivil_03/_ato2011-2014/2014/lei//13005.htm>. Acesso em: 13 dez. 2017.

BRASIL. Lei n 9.424 de 24 de dezembro de 1996. Dispõe sobre o Fundo de Manutenção e Desenvolvimento do Ensino Fundamental e de Valorização do Magistério, na forma prevista no art. $60, \S 7^{\circ}$, do Ato das Disposições Constitucionais Transitórias, e dá outras providências. Diário Oficial da União, Brasília, 26 dez. 1996. Disponível em: <http://www.planalto.gov.br/ccivil_03/leis/L9424compilado.htm>. Acesso em: 12 dez. 2017. BRASIL. Lei no11.741 de 16 julho de 2008. Altera dispositivos da Lei no 9.394, de 20 de dezembro de 1996, que estabelece as diretrizes e bases da educação nacional, para redimensionar, institucionalizar e integrar as ações da educação profissional técnica de nível médio, da educação de jovens e adultos e da educação profissional e tecnológica. Diário Oficial da União, Brasília, 17 jul. 2008a. Disponível em: <http://www.planalto.gov.br/CCIVIL_03/_ATO2007-2010/2008/LEI/L11741.HTM>. Acesso em: 02 nov. 2017.

BRASIL. Ministério da Educação. Plano Nacional de Educação - PNE. Brasília: INEP, $2001 . \quad$ Disponível em: $<$ http://portal.inep.gov.br/documents/186968/484421/Plano+Nacional+de+Educa\%C3\%A7\% $\mathrm{C} 3 \% \mathrm{A3O}+-$ +PNE+subs $\%$ C3\%ADdios+para+a+elabora\%C3\%A7\%C3\%A30+dos+planos+estaduais+e+ 
municipais+de+educa\%C3\%A7\%C3\%A3o/276d3397-1928-400e-8524-

9a4e0fd1453d?version=1.2> Acesso em: 05 dez. 2017.

BRASIL. Ministério da Educação. Resolução no 4, de 5 de outubro de 1999. Institui as Diretrizes Curriculares Nacionais para a Educação Profissional de Nível Técnico. Diário Oficial da União, Brasília, 26 de nov. de 1999. Disponível em: <http://portal.mec.gov.br/setec/arquivos/pdf/RCNE_CEB04_99.pdf >. Acesso em: 13 dez. 2017.

BRASIL. Ministério da Educação. Resolução no 6, de 20 de setembro de 2012. Define Diretrizes Curriculares Nacionais para a Educação Profissional Técnica de Nível Médio. Diário Oficial da União, Brasília, 21 de set. de 2012a. Disponível em: $<$ http://portal.mec.gov.br/index.php?option=com_docman\&view=download\&alias=11663rceb006-12-pdf\&category_slug=setembro-2012-pdf\&ltemid=30192>. Acesso em: 01 nov. 2017.

BRASIL. Ministério da Educação. Secretaria de Educação Profissional e Tecnológica. Plano de ação para o cumprimento das determinações do Acórdão no 506/2013 - TCU Plenário. Brasília, 13 set. 2013.

BRASIL. Presidência da República. Secretaria de Governo. Ensino profissional. Disponível em:

<http://www.secretariadegoverno.gov.br/iniciativas/internacional/fsm/eixos/educacao/ensinoprofissional>. Acesso em: $13 \mathrm{dez} .2017$

BRASIL. Tribunal de Contas da União. Relatório de auditoria operacional em ações da rede federal de educação profissional, científica e tecnológica. Brasília: TCU/Seprog, $2012 f$.

CASTIONI, R. O papel dos Institutos Federais na promoção do desenvolvimento local. In: SOUZA, E. C. L.; CASTIONI, R. Institutos Federais: os desafios a institucionalização. Brasília: EDU-UNB, 2012. p. 45-56.

CASTRO, C. M. O ensino médio: órfão de idéias, herdeiro de equívocos. Ensaio: aval. pol. públ. Educ., Rio de Janeiro, v. 16, n. 58, p. 113-124, jan./ mar. 2008.

DORE, R.; LÜSCHER, A. Z. C. Education and Training of 15-20 years-old in Brazil. Revista Formazione \& Insegnamento. Ano VI, n. 1/2, Veneza, 2008, p.163-194.

DUARTE, M. R. T.; SANTOS, M. R. S. Planejamento da educação nacional no Brasil: da educação do povo à regulação do sistema educacional federativo. In: SOUZA, D. B. de; DUARTE, M. R. T.; OLIVEIRA, R. de F. (Orgs.). Sistemas educacionais: concepções, tensões, desafios. São Paulo: Edições Loyola, 2015, p. 83-104.

DUARTE, M. R. T.; SANTOS, M. R. S. Planejamento e participação: os eventos nacionais na área da educação após a Constituição de 1988. Revista Educação (PUCRS), v. 37, p. 167179, 2014a. 
DUARTE, M. R. T.; SANTOS, M. R. S. Sistema Nacional de Educação e relações intergovernamentais no Brasil. Educação \& Sociedade, Campinas, v. 35, p. 1115-1136. out.-dez. 2014b.

GRAMSCI, A. Cadernos do cárcere. Tradução de Carlos Nelson Coutinho. Rio de Janeiro: Civilização Brasileira, vol. 2, 3a. edição, 2004.

INSTITUTO NACIONAL DE ESTUDOS E PESQUISAS EDUCACIONAIS ANÍSIO TEIXEIRA. Sinopse Estatísticas da Educação Básica 2015. Brasília: INEP, 2016. Disponível em: $<$ http://portal.inep.gov.br/basica-censo-escolar-sinopse-sinopse>. Acesso em: 20 nov. 2017. MORAES, G. H. Identidade de escola técnica vs. vontade de universidade a formação da identidade dos Institutos Federais. 2016. 356 p. Tese (Doutorado em Educação) Faculdade de Educação, Universidade de Brasília, Brasília, 2016.

OTRANTO, C. R. A Política de Educação Profissional do Governo Lula. In: da 34를 REUNIÃO ANUAL DA ANPED, 34., Natal, RN, 2011. Anais eletrônicos... Natal, RN, 2011.

PACHECO, E. Prefácio: Institutos Federais: um futuro em aberto. In: SOUZA, E. C. L.; CASTIONI, R. Institutos Federais: os desafios a institucionalização. Brasília: EDU-UNB, 2012.

RAMOS, M. A pedagogia das competências: autonomia ou adaptação? São Paulo: Cortez Editora. 2002.

REIS JUNIOR, R. de L. Os limites da experiência de Estado desenvolvimentista no Brasil (2003-2015): o caso dos Institutos Federais. 2017. 266 p. Tese (Doutorado em Educação) - Faculdade de Educação, Universidade de Brasília, Brasília, 2017.

SILVA FILHO, G. A.; MORAES, G. H. Comparando desempenhos de diferentes tipos de escola de ensino médio: uma aproximação de medida de valor adicionado. Boletim na medida. Ano 6. no 12. Brasília: INEP/MEC. ago. de 2017. p. 21-30.

SILVA, C. J. R.; et al. (Org.) Institutos Federais lei 11.892, de 29/12/2008: comentários e reflexões. Brasília: IFRN editora, 2009.

SILVA, J.; ALMEIDA, R.; STROKOVA, V. Sustentando melhorias no emprego e nos salários no Brasil: uma agenda de competências e empregos. Washington: The World Bank, 2015.

SOUZA, C. Governos locais e gestão de políticas sociais universais. São Paulo em Perspectiva, v. 18, n. 2, p. 27-41, 2004. 